\title{
10. RadiologieKongressRuhr - Programm und Anmeldung online!
}

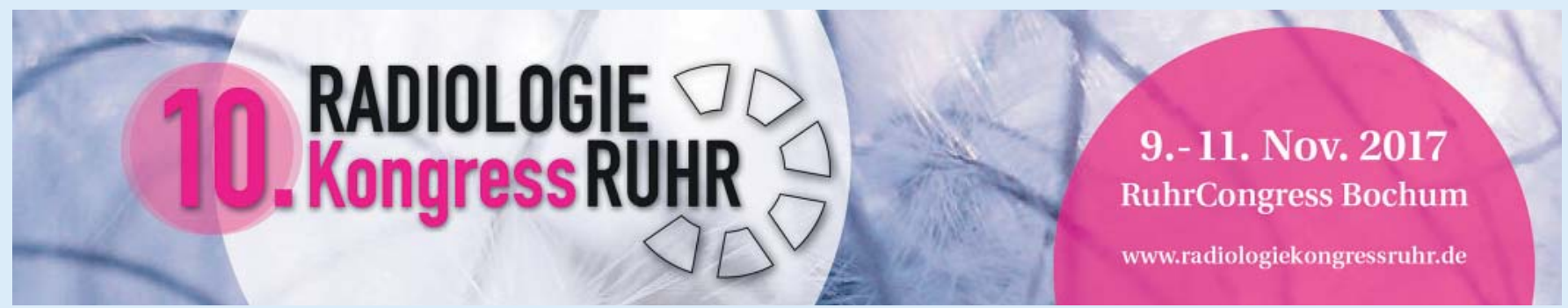

Ab sofort finden Sie das Jubiläumsprogramm des 10 . RKR auf www.radiologiekongressruhr.de sowie die Möglichkeit zur Anmeldung. Mitglieder von DRG, DGN und RWRG profitieren von vergünstigten Ticketpreisen. Bis zum 31. August 2017 erhalten Sie zudem einen Rabatt auf alle 3-Tagestickets.

\section{Kongress-Schwerpunkte}

Das 10-jährige Jubiläum des RKR findet seinen Niederschlag im Kongressprogramm. Im Hauptprogramm erwarten Sie hochkarätige Vorträge von renommierten Referen- tinnen und Referenten zu aktuellen Themen der Radiologie, wie Leber-Interventionen, Mammadiagnostik und -Interventionen, Neuroradiologie, Muskuloskelettale Radiologie, Onkologie, Kinderradiologie u.v.m. Auch MTRA, MTRA-SchülerInnen und Medizinstudierende werden mit eigens für sie konzipierten Programmsessions wieder auf ihre Kosten kommen.

\section{Highlight-Session}

Im Rahmen einer Highlight-Session mit internationaler Strahlkraft möchten wir
Ihnen einen spannenden Blick auf die Welt der Radiologie und darüber hinaus bieten. Prof. Dr. Claus Claussen aus Tübingen wird in diesem Rahmen über das aktuelle Thema „Welche Chancen bietet die personalisierte Medizin für die Radiologie?" sprechen.

Alle Informationen zum Programm und zur Anmeldung finden Sie auf der Homepage www.radiologiekongressruhr.de. 